\title{
Overexpression of the immediate early response 5 gene increases the radiosensitivity of HeLa cells
}

\author{
KU-KE DING ${ }^{1,2}$ FEN YANG $^{3}$, HUI-QING JIANG ${ }^{3}$, ZENG-QIANG YUAN ${ }^{4}$, \\ LING-LING YIN ${ }^{3}$, LING-YUE DONG ${ }^{5}$, WEI CUI ${ }^{5}$, QIAO GOU ${ }^{1,2}$, XIAO-DAN LIU $^{6}$, YU-MEI WU ${ }^{7}$, \\ XIAO-YAN JIANG ${ }^{1,2}$, XIN ZHANG $^{8}$, PING-KUN ZHOU ${ }^{6}$ and CHUAN-JIE YANG ${ }^{3}$
}

${ }^{1}$ National Institute for Radiological Protection; ${ }^{2}$ Key Laboratory of Radiological Protection and Nuclear Emergency, Chinese Center for Disease Control and Prevention, Beijing 100088; ${ }^{3}$ Department of Gastroenterology,

The Second Hospital of Hebei Medical University, Shijiazhuang, Hebei 050000; ${ }^{4}$ Institute of Biophysics, The Chinese Academy of Sciences, Beijing 100101; ${ }^{5}$ Biomedical Engineering School and Foundation Medical School, Capital Medical University, Beijing 100069; ${ }^{6}$ Department of Radiation Toxicology and Oncology, Beijing Institute of Radiation Medicine, Beijing 100850; ${ }^{7}$ Department of Gynecological Oncology, Beijing Obstetrics and Gynecology Hospital, Capital Medical University, Beijing 100006; ${ }^{8}$ Department of Gynecology, Liaoning Cancer Hospital and Cancer Hospital of China Medical University, Shenyang, Liaoning 110042, P.R. China

Received July 18, 2018; Accepted June 13, 2019

DOI: $10.3892 / \mathrm{ol} .2019 .10590$

\begin{abstract}
The effects of the immediate early response 5 (IER5) gene on the sensitivity of HeLa cells to radiation remain unclear. In the present study, stably transfected HeLa cells resulting in the knockdown or overexpression of IER 5 were investigated. In addition, xenografts of normal, IER 5-silenced and -overexpressed HeLa cells were injected into nude mice and examined. The results demonstrated that the radiosensitivity of the IER5-overexpressed HeLa cells was significantly increased compared with that of the normal and IER5-silenced cells. The upregulation of IER 5 effectively decreased cell proliferation and IER 5 silencing promoted cell proliferation compared with that in the normal HeLa cells. Following irradiation of the cells with IER5 knockdown, cell cycle was arrested at the $\mathrm{G}_{2} / \mathrm{M}$ phase and an increase in the proportion of $\mathrm{S}$ phase cells was observed. By contrast, the overexpression of IER5 led to an increase in the proportion of $\mathrm{G}_{1}$ phase cells. Furthermore, the upregulation of IER5 inhibited tumor growth in vivo. The present findings demonstrate that the IER5 gene affects the radiosensitivity of HeLa cells and serves an important role in cell proliferation, suggesting that this gene may be a potential radiotherapeutic target in cervical cancer.
\end{abstract}

Correspondence to: Dr Chuan-Jie Yang, Department of Gastroenterology, The Second Hospital of Hebei Medical University, 215 West Heping Road, Shijiazhuang, Hebei 050000, P.R. China E-mail: yangchuanjie2004@sina.com

Key words: immediate early response 5 gene, HeLa cells, radiosensitivity, cell proliferation, xenograft

\section{Introduction}

Cervical cancer is a malignant neoplasm of the cervix. It may present with vaginal bleeding but is often asymptomatic until the cancer is in its advanced stages $(1,2)$. The methods of treatment for this cancer consist of surgery (including local excision) in the early stages, and chemotherapy and radiotherapy in the advanced stages. Radiotherapy uses certain types of radiation, including $\mathrm{X}$-rays, $\gamma$-rays or particles, to shrink tumors or eliminate cancer cells by damaging DNA and subsequently causing cell death or the inability to proliferate. In recent years, attempts have been made to identify radiation-sensitive genes for the purpose of elucidating the complex mechanisms of cellular responses to ionizing radiation, or for the identification of biomarkers for radiosensitive individuals (3-5). Previous studies have performed microarray analysis on various types of normal and cancer cells, including HeLa cells $(6,7)$. The expression of the immediate early response 5 (IER5) gene has been revealed to change in a dose- and time-dependent manner in various types of cells, following radiation (6).

However, the effect of the atypical expression of IER5 in HeLa cells on radiosensitivity and tumor growth remain unclear. In order to understand the role of the IER5 gene in radiotherapy for cervical cancer in the present study, RNA interference technology was used to silence IER5 in HeLa cells, and overexpression plasmids were used to upregulate the gene. The results of these experiments indicated that the expression of IER5 is involved in the radiation-induced cell death. In addition, 5-week-old BALB/C nude mice were inoculated with three types of HeLa cells (normal, IER5-knockdown and IER 5-overexpression) and the sizes of the resulting tumors were recorded. Based on these investigations and observations, the response of IER5 expression to $\gamma$-ray radiation was examined, as was its involvement in cell cycle checkpoint control and cell survival. 


\section{Materials and methods}

Cell culture. Three versions of HeLa cells (obtained by the Laboratory of Beijing Institute of Radiation Medicine), including unmodified cells, cells transfected with small interfering (si)RNA targeting IER5 mRNA (IER5-siRNA-HeLa) and cells overexpressing IER5 (IER5-overexpression-HeLa), were cultured in Dulbecco's modified Eagle's medium (DMEM; Invitrogen; Thermo Fisher Scientific, Inc.), supplemented with $10 \%$ fetal bovine serum (PAN-Seratech, Inc.), $100 \mathrm{U} / \mathrm{ml}$ penicillin and $100 \mathrm{~g} / \mathrm{ml}$ streptomycin. The cells were cultured in a humid atmosphere with $5 \% \mathrm{CO}_{2}$ at $37^{\circ} \mathrm{C}$.

Irradiation. The exponentially growing cells were irradiated with $1.7 \mathrm{~Gy} / \mathrm{min}$ for $2.4 \mathrm{~min}$ (total 4Gy) or $1.2 \mathrm{~min}$ (total $2 \mathrm{~Gy}$ ), using a ${ }^{60} \mathrm{Co} \gamma$-ray source at room temperature. For the mock radiation control, the cells were placed in the radiation room for the same duration as the corresponding treatment groups, but the cobalt source remained underwater and was barricaded. Following irradiation, the cells were cultured, harvested and prepared for the subsequent experiments.

RNA isolation and reverse transcription (RT). Total RNA was isolated from the irradiated and mock-irradiated cells using TRIzol reagent (Invitrogen; Thermo Fisher Scientific, Inc., Waltham, MA, USA) according to the manufacturer's protocol. The total RNA concentration was determined using spectrometry, and the quality was determined by $1 \%$ formaldehyde agarose gel electrophoresis. Total RNA was reverse transcribed into cDNA using a ProtoScript ${ }^{\mathrm{TM}}$ First Strand cDNA Synthesis kit (New England BioLabs, Inc., Ipswich, MA, USA), according to the manufacturer's protocol. The synthesized cDNA was stored at $-80^{\circ} \mathrm{C}$ and analyzed directly by quantitative polymerase chain reaction (qPCR) analysis.

The sequences of siRNAs targeting the IER 5 gene (GenBank accession no. NM_016545) were analyzed using the Basic Local Alignment Search Tool (https://blast.ncbi.nlm.nih. gov/Blast.cgi) to ensure they did not target any other gene transcripts. Two siRNAs targeting IER 5 mRNA were screened and the oligonucleotides were synthesized. The sequences encoding IER 5 siRNA were as follows (targeting sequences are underlined): IER5-27 siRNA, sense 5'-GATCCGCCTCATCAGCAT CTTCGGTTTCAAGAGAACCGAAGATGCTGATGAGGT TTTTTGGAAA-3' and antisense 5'-AGCTTTTCCAAAAAA CCTCATCAGCATCTTCGGTTCTCTTGAAACCGAAGA TGCTGATGAGGCG-3'; IER5-16 siRNA, sense 5'-GATCCG CTGCATAAGAACCTCCTGTTCAAGAGACAGGAGGTT CTTATGCAGCTTTTTTGGAAA-3' and antisense 5'-AGC TTTTCCAAAAAAGCTGCATAAGAACCTCCTGTC TCTTGAACAGGAGGTTCTTATGCAGCG-3'. HindIII and BamHI restriction sites were added upstream and downstream of each oligonucleotide. Following annealing, these duplex oligonucleotides were inserted between the HindIII and BamHI sites of the pSilencer ${ }^{\mathrm{TM}} 3.1$ vector (Ambion; Thermo Fisher Scientific, Inc.) to generate pSilencerIER5 siRNA vectors. All constructs were sequence-verified prior to use. A vector containing the following non-specific siRNA (NSsiRNA) was used as the experimental control: NSsiRNA, sense 5'-GAT CCCACTACCGTTGTTATAGGTGTTCAAGAGACACCT ATAACAACGGTAGTTTTTTTTGGAAA-3' and antisense
5'-AGCTTTTCCAAAAAAAACTACCGTTGTTATAGGTGT CTCTTGAACACCTATAACAACGGTAGTGG-3'.

Cell transfection. For vector DNA transfection, the HeLa cells were plated in $60-\mathrm{mm}$ Petri dishes at a density of $5 \times 10^{5}$ cells per dish. The cells were transfected with the pSilencerIER5 siRNA vector using Lipofectamine 2000 (Invitrogen, Carlsbad, CA, USA) reagent $24 \mathrm{~h}$ after plating, according to the manufacturer's protocol. The transfected cultures were sub-cultured into new $60-\mathrm{mm}$ dishes after $24 \mathrm{~h}$ and maintained in conditioned DMEM supplemented with $250 \mu \mathrm{g} / \mathrm{ml}$ hygromycin B (Roche Diagnostics, Basel, Switzerland) to select for transfected clones.

Construction of IER5-overexpression vectors. Based on the GenBank IER5 gene sequence, the following primers were designed for PCR amplification of a 986-bp segment: Sense 5'-GACGAATTCAATGGAGTTCAAGCTG-3' and antisense 5'-GTAGCACCGGAAGACTAGATCTCAG-3'. The plasmid for the overexpression of IER (defined as IER 5-overexpression) was constructed by PCR, and the 986-bp amplicon was inserted into the EcoRI-XbaI site of the pCMV-3xFLAG vector (Sigma-Aldrich; Merck KGaA, Darmstadt, Germany) using Lipofectamine 2000 (Sigma-Aldrich; Merck KGaA), according to the manufacturer's protocol. Briefly, HeLa cells $\left(\sim 1.5 \times 10^{4}\right)$ were plated in 6 -well plates and growth medium was removed from the plates when the cells reached $\sim 80 \%$ confluence. A total of $500 \mu \mathrm{l}$ transfection mixture containing $1.25 \mu \mathrm{g}$ plasmid DNA and $3.75 \mu \mathrm{l}$ Lipofectamine 2000 reagent was added to the plates. The cells were incubated at $37^{\circ} \mathrm{C}$ for $5 \mathrm{~h}$, gently overlaid with $2 \mathrm{ml}$ pre-warmed complete growth medium and incubated for an additional 5 days. The transfected cells were then cultured in medium containing $400 \mu \mathrm{g} / \mathrm{ml}$ neomycin (G418) for 14 days for stress selection. The selective media were replaced every 3-4 days. The surviving transfected cells localized in distinct 'islands' were maintained with growth medium. Individual clones were transferred to 96-well plates for proliferation using standard techniques (cloning cylinders). The vector without the IER 5 gene fragment was used as a control (Non-IER5-overexpressing). Stable transfectants were used in the subsequent experiments.

Determination of $m R N A$ and protein expression levels of IER5. For confirmation, the expression levels of IER5 in the transfectants were measured using RT-qPCR and western blot analyses. The mRNA levels were quantified by RT-qPCR analysis using an ABI 7300 Real-Time PCR system (Applied Biosystems; Thermo Fisher Scientific, Inc.). The reaction mixture contained $10 \mu 1$ DyNAmo $^{\mathrm{TM}}$ SYBR $^{\circledR}$ Green qPCR Master mix containing the modified Thermus brockianus hot-start DNA polymerase (Finnzymes Oy, Espoo, Finland), $0.2 \mu \mathrm{M}$ each primer and $2 \mu \mathrm{l} \mathrm{cDNA}$ template (obtained by reverse transcription, as described above), to a final volume of $20 \mu \mathrm{l}$. The RT-qPCR was performed in accordance with the conditions: $95^{\circ} \mathrm{C} 5 \mathrm{~min} ; 35 \mathrm{PCR}$ cycles $\left(95^{\circ} \mathrm{C}, 5 \mathrm{sec} ; 57^{\circ} \mathrm{C}\right.$, $15 \mathrm{sec} ; 72^{\circ} \mathrm{C}, 15 \mathrm{sec}$ ); extension at $72^{\circ} \mathrm{C}$ for $5 \mathrm{~min}$ and the cycle at which the fluorescent signal crossed the detection threshold was denoted as the cycle threshold. Relative mRNA levels normalized to endogenous $\beta$-actin mRNA levels are presented relative to IER5 mRNA levels using the $2^{-}{ }^{\Delta \Delta \mathrm{Cq}}$ method (8). 
Each PCR was run in triplicate in three independent experiments. The primers for amplification of human IER5 were as follows: Forward 5'-CCGGGAACGTGGCTAACC-3' and reverse 5'-TTCCGTAGGAGTCCCGAGAA-3'; and those for human $\beta$-actin were as follows: Forward 5'GCGCGGCTA CAGCTTCA-3' and reverse 5'-CTTAATGTCACGCACGAT TTCC-3'.

For the western blot analysis, the cells were harvested, washed three times with PBS and then lysed using RIPA buffer. The protein concentrations were determined using a BCA protein assay kit (Thermo Scientific Pierce, Micro $\mathrm{BCA}^{\mathrm{TM}}$ Protein Assay kit). Equal quantities of total protein (60 $\mu \mathrm{g}$ per lysate) were separated by $10 \%$ sodium dodecylsulfate-polyacrylamide gel electrophoresis and electroblotted onto a nitrocellulose membrane. The nitrocellulose membrane was then placed in 5\% blocking buffer made up with skim milk powder at room temperature for $1-2 \mathrm{~h}$ on the shaker. The membrane was first hybridized with antibody against IER5 (cat. no. ARP56939-P050; Santa Cruz Biotechnology, Inc., Santa Cruz, CA, USA) and $\beta$-actin (cat. no. 4970; Cell Signaling Technology, Inc., Beverly, MA, USA) overnight at $4^{\circ} \mathrm{C}$. The dilution ratio of antibody to IER5 and $\beta$-actin was 1:1,000 and 1:5,000, respectively. The hybridized nitrocellulose membrane was washed with 1xTBST (0.1\% Tween) for 5 times, each time for $8 \mathrm{~min}$, followed by incubation with the sheep anti-mouse (cat. no. A0408; Beyotime Institute of Biotechnology, Beijing, China) diluted to $1: 3,000$ for $1 \mathrm{~h}$ at room temperature. The specific band that reflected the IER5 protein was visualized with enhanced chemiluminescence (ECL) reagents (GE Healthcare, Chicago, IL, USA), followed by subsequent exposure of the blot onto a film (Eastman Kodak Company, Rochester, NY). The protein loading was standardized using $\beta$-actin. The films were developed using ECL methods.

Cell proliferation and clonogenic survival analysis. For the cell proliferation assays, $1.5 \times 10^{4}$ cells per well were seeded in 6-well culture plates, cultured for $24 \mathrm{~h}$ and subjected to $\gamma$-ray irradiation. The cell numbers in three wells were counted every day following radiation. The culture medium was replaced on day 3. Three independent experiments were performed, and the mean cell numbers were used to generate a growth curve.

For the clonogenic survival assays, exponentially growing cells were collected and diluted into appropriate concentrations and exposed to a ${ }^{60} \mathrm{Co} \gamma$-ray source at a dose rate of $1.74 \mathrm{~Gy} \mathrm{~min}^{-1}$. The corresponding controls were mock-irradiated. Immediately following radiation, an appropriate number of cells (100-2,000, depending on the radiation dose) were plated into 60-mm diameter Petri dishes. Each experiment was performed in triplicate. The culture medium was replaced 1 week post-radiation. After 12 days of culture, the cells were mixed with methanol for $5 \mathrm{~min}$ at room temperature, stained with Giemsa solution for $3 \mathrm{~min}$ at $37^{\circ} \mathrm{C}$, and colonies that consisted of $>50$ cells were counted by laser confocal microscope (magnification, $\mathrm{x} 400$; Olympus Coorperation).

Cell cycle analysis by flow cytometry. Following irradiation with a dose of $2 \mathrm{~Gy}$, the cells were harvested at the designed time point and mixed with $75 \%$ ethanol. The cells were then resuspended in PBS with $0.1 \%$ saponin and $1 \mu \mathrm{g} / \mathrm{ml}$ RNase A
(Sigma-Aldrich; Merck KGaA), incubated for $20 \mathrm{~min}$ at $37^{\circ} \mathrm{C}$ and stained with $25 \mu \mathrm{g} / \mathrm{ml}$ propidium iodide (PI; Sigma-Aldrich; Merck KGaA). Cell cycle distribution was evaluated by flow cytometry ( $>10,000$ cells per sample). For the detection of cell mitosis, the fixed cells were treated with $0.5 \%$ Triton $\times 100$ for $15 \mathrm{~min}$ and incubated in PBS containing $0.5 \mu \mathrm{g} / \mathrm{ml}$ mouse monoclonal antibody against $\mathrm{H} 3$ pSer10 (cat. no. 53348; Cell Signaling Technology, Inc., Danvers, MA, USA) for $30 \mathrm{~min}$ at room temperature. Following two washing steps with PBS, the cells were incubated with fluorescein isothiocyanate-conjugated goat anti-mouse secondary antibody (cat. no. TA130013; OriGene Technologies, Inc., Beijing, China) for $30 \mathrm{~min}$ at room temperature, and resuspended in PBS containing $10 \mu \mathrm{g} / \mathrm{ml} \mathrm{PI}$ and $10 \mu \mathrm{g} / \mathrm{ml} \mathrm{RNase} \mathrm{A}$ at $37^{\circ} \mathrm{C}$ for $1 \mathrm{~h}$ in the dark. The volume ratio of antibody against $\mathrm{H} 3$ pSer10 and the secondary antibody to $1 \%$ bovine serum albumin solution was 1:400 and 1:200, respectively. The stained cells were analyzed by flow cytometry. Two independent experiments were performed.

Tumorigenic ability of cells. Adult male BALB/c-nu host mice (5 weeks old; $\sim 15 \mathrm{~g}$ weight; Beijing Vital River Laboratory Animal Technology Co., Ltd.) were housed and cared for in compliance with the regulations of the Ministry of Health and the Experimental Animal Center of Capital Medical University (Beijing, China). The Committee for Animal Use at the Capital Medical University approved all experimental procedures performed in the present study. Water and food were available ad libitum in the cages. The ambient temperature was $22^{\circ} \mathrm{C}$, relative humidity was $60 \%$ and the air was changed every $12 \mathrm{~h}$. The mice were allowed to acclimate for 1 week prior to treatment.

The three cell lines (IER5-siRNA-HeLa, HeLa and IER5-overexpression-HeLa) were cultured in DMEM containing $10 \%$ fetal bovine serum in an incubator with $5 \%$ $\mathrm{CO}_{2}$ at $37^{\circ} \mathrm{C}$. The exponentially growing cells were trypsinized with $0.25 \%$ trypsin digestion and washed twice with $1 \mathrm{X}$ PBS. Following centrifugation at $1,000 \mathrm{x}$ g for $3 \mathrm{~min}$ at room temperature, the three cell lines were suspended and $1 \times 10^{7}$ cells per cell line were injected into the front armpits of BALB/c-nu nude mice (the inoculation sites on the nude mouse skin were disinfected with tincture of iodine and alcohol prior to inoculation) using the sterile syringes, each with $0.5 \mathrm{ml}$ cell suspension (containing $\sim 1 \times 10^{7}$ cells).

The above experiment was repeated three times with three different groups. Each animal was inoculated with $1 \times 10^{7}$ cells, which grew into tumors under their skin. On day 28 of inoculation of the nude mice with the above-mentioned cells, the mice were removed for weighing and injected with sodium pentobarbital into the abdominal cavity at a dose of $50 \mathrm{mg} / \mathrm{kg}$. In their anesthetized state, the mice were sacrificed by cervical dislocation, following which the tumors were weighed on being removed from under the skin.

Statistical analysis. One-way analysis of variance (ANOVA) and two-tailed t-tests were used to compare differences among groups. The Student-Newman-Keuls test was used as the post hoc test following ANOVA. $\mathrm{P}<0.05$ was considered to indicate a statistically significant difference. Statistical analyses were performed using SPSS 19.0 software (IBM Corp., Armonk, 
Table I. mRNA expression levels of IER5 in IER5-silenced HeLa cells determined by reverse transcription-quantitative polymerase chain reaction analysis.

\begin{tabular}{lccccc}
\hline Sample & IER5 Cq & $\beta$-actin Cq & $\Delta \mathrm{Cq}$ & $\Delta \Delta \mathrm{Cq}$ & siRNA/control $\left(2^{-\Delta \Delta \mathrm{Cq})}\right.$ \\
\hline $27^{\text {siRNA_C1 }}$ & 23.139 & 19.476 & 3.914 & 4.372 & $2^{-4.372}$ \\
$27^{\text {siRNA_C2 }}$ & 24.276 & 15.985 & 8.291 & 8.794 & $2^{-8.794}$ \\
$27^{\text {siRNA_C3 }}$ & 23.076 & 15.594 & 7.482 & 7.940 & $2^{-7.94}$ \\
$27^{\text {siRNA_C4 }}$ & 23.595 & 21.390 & 2.205 & 2.663 & $2^{-2.663}$ \\
$16^{\text {siRNA_C1 }}$ & 24.675 & 21.877 & 2.798 & 3.256 & $2^{-3.256}$ \\
NS $^{\text {siRNA_C1 }}$ & 23.614 & 31.524 & -7.910 & -6.452 & $2^{+6.452}$ \\
Control & 31.342 & 31.800 & -0.458 & $<0.001$ & $2^{0}=1$
\end{tabular}

Data presented are the mean values from three independent detections. IER5, immediate early response 5; siRNA, small interfering RNA; NS, non-specific.

NY, USA). Data are presented as the mean \pm standard error of the mean in all figures.

\section{Results}

Cell lines with atypical expression of IER5. Two siRNA molecules targeting IER5 were designed and separately transfected into HeLa cells, and a number of stably transfected clones $\left(27^{\text {siRNA }}-\mathrm{C} 1,27^{\text {siRNA }}-\mathrm{C} 2,27^{\text {siRNA }}-\mathrm{C} 3,27^{\text {siRNA }}-\mathrm{C} 4,16^{\text {siRNA }}-\mathrm{C} 1\right.$ and $\left.\mathrm{NS}^{\text {siRNA }}-\mathrm{C} 1\right)$ were selected. The total RNA was isolated and used to quantify the expression level of IER5 by RT-qPCR analysis. As demonstrated in Table I, the expression of IER5 in clone $27^{\text {siRNA }}-\mathrm{C} 2$ was suppressed the most. This clone was derived from HeLa cells transfected with the IER5-27 siRNA vector. In addition, western blot analysis revealed that the protein expression of IER5 in clone $27^{\text {SiRNA }}-\mathrm{C} 2$ was markedly lower than that in the $\mathrm{NS}^{\text {siRNA }}-\mathrm{C} 1$ and untransfected HeLa cells. Therefore, the $27^{\text {siRNA }}-\mathrm{C} 2$ clone was selected for subsequent investigation of the influence of the inhibited expression of IER 5 on the cellular response to radiation and was labeled IER5-siRNA-HeLa. Subsequently, the $27^{\text {siRNA }}-\mathrm{C} 2$, NS ${ }^{\text {siRNA }}-\mathrm{C} 1$ and untransfected HeLa cells were separately exposed to radiation. As shown in Fig. 1, western blot analysis revealed that the NSsiRNA-C1 and untransfected HeLa cells had higher protein expression of IER5, whereas the $27^{\text {siRNA }}-\mathrm{C} 2$ HeLa cells exhibited no notable increase in IER 5 protein.

Three IER 5-overexpression clones, $3^{\text {overexpression }} \mathrm{C} 1$, $3^{\text {overexpression }}-\mathrm{C} 2$ and $3^{\text {overexpression }}-\mathrm{C} 3$, were selected. The total RNA from each clone was isolated and used to quantify the expression of IER5 by RT-qPCR analysis. Table II demonstrates that the expression of IER5 was highest in clone $3^{\text {overexpression }}-\mathrm{C} 2$, which was generated from cells transfected with IER5-overexpression-3. Therefore, clone $3^{\text {overexpression }}-\mathrm{C} 2$ was selected for the subsequent experiments, and labeled as IER5-overexpression-HeLa cells.

Overexpression of IER5 decreases the proliferation and survival of HeLa cells following radiation. First, the proliferation abilities of the IER5-siRNA-HeLa and IER5-overexpression-HeLa cells were investigated. On day 6 post-seeding, the IER5-siRNA-HeLa cells exhibited significantly higher proliferation than the normal HeLa cells

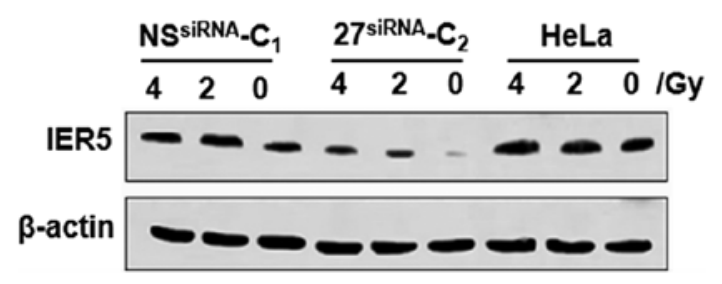

Figure 1. Protein expression levels of IER5 in three types of HeLa cells were detected by western blotting. IER5, immediate early response 5; siRNA, small interfering RNA; NSsiRNA, non-specific siRNA.

(Fig. 2A and B). By contrast, the proliferation rate of the IER5-overexpression-HeLa cells was lower than that of the normal HeLa cells.

Furthermore, the influence of atypical expression of IER5 on the proliferation of HeLa cells following irradiation was examined. The clonogenic survival assay demonstrated that the overexpression of IER5 significantly increased the sensitivity of HeLa cells to radiation (with $0.5,1,2,4$ and 6 Gy) compared with normal expression of IER5 (Fig. 3). By contrast, the survival rate of the IER5-siRNA-HeLa cells following radiation was higher than that of the normal HeLa cells. These results indicate that the overexpression of IER 5 suppressed the growth of HeLa cells and increased the radiosensitivity of HeLa cells.

Overexpression of IER5 induces $G_{0} / G_{1}$ arrest in HeLa cells. The results of the flow cytometry demonstrated that a higher percentage of the IER5-overexpression-HeLa cells were in the $\mathrm{G}_{0} / \mathrm{G}_{1}$ phase compared with that for the normal or IER5-siRNA-HeLa cells, either prior to or following radiation (Fig. 4A). The fraction of cells in the $G_{0} / G_{1}$ phase was the smallest for the cells with downregulated IER5. As shown in Fig. 4B, the proportion of IER5-siRNA-HeLa cells in the $\mathrm{G}_{2} / \mathrm{M}$ phase following radiation was higher than that for the other two cell types, and the proportion in the IER5-overexpression-HeLa cells was lowest at $12 \mathrm{~h}$ post-radiation. The number of cells in the $S$ phase was higher in the normal HeLa cells following irradiation (Fig. 4C).

Inhibition of IER5 promotes tumorigenesis in nude mice. The mice were sacrificed 4 weeks after inoculation of the 
Table II. mRNA expression levels of IER5 in IER5-overexpressed HeLa cells determined by reverse transcription-quantitative polymerase chain reaction analysis.

\begin{tabular}{lccccc}
\hline Sample & IER5 Cq & $\beta$-actin Cq & $\Delta \mathrm{Cq}$ & $\Delta \Delta \mathrm{Cq}$ & $\begin{array}{c}\text { IER5-overexpression-HeLa/ } \\
\text { control }\left(2^{-\Delta \Delta \mathrm{Cq})}\right.\end{array}$ \\
\hline $3^{\text {overexpression_C1 }}$ & 17.245 & 22.142 & -4.897 & -4.001 & $2^{4.001}$ \\
$3^{\text {overexpression }}$-C2 & 17.823 & 23.639 & -5.816 & -4.920 & $2^{4.920}$ \\
$3^{\text {overexpression_C3 }}$ & 18.502 & 21.674 & -3.172 & -2.276 & $2^{2.276}$ \\
Control & 32.3672 & 33.258 & -0.896 & $<0.001$ & $2^{0}=1$ \\
\hline
\end{tabular}

Data presented are the mean values from three independent detections. IER5, immediate early response 5.
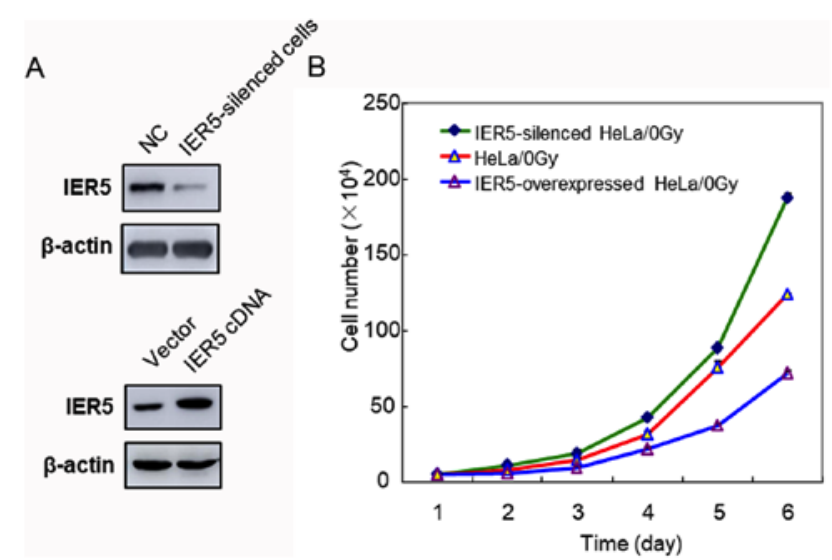

Figure 2. Proliferation of cells in IER5-silenced and IER5-overexpressed HeLa cells. (A) Western blot analyses were performed to determine the expression of IER5 in IER5-silenced HeLa cells and IER5-overexpressed HeLa cells. (B) Proliferation of the three types of HeLa cells was measured by cell counting at designed time points post-seeding. IER5, immediate early response 5; $\mathrm{NC}$, negative control.

three cell types, and any resulting tumors were weighed. The average weight of the xenograft tumors resulting from the IER5-siRNA-HeLa cells was markedly higher than that of tumors derived from the normal or IER5-overexpression-HeLa cells (Fig. 5A-C). The maximum diameter of a single subcutaneous tumor was $8.3 \times 14.2 \times 11.2 \mathrm{~mm}\left(1.32 \mathrm{~mm}^{3}\right)$, and the average size of the fastest growing type of tumor was $1.0 \mathrm{~mm}^{3}$. The smallest tumors were observed in the mice inoculated with IER5-overexpression-HeLa cells.

\section{Discussion}

Radiotherapy is particularly effective against tumors, and is one of the three conventional methods of tumor treatment. This method can effectively prevent the growth of certain tumors and prolong the life of a patient. However, radioresistance is a major obstacle in radiation treatment (9-11). In order to improve the quality and sensitivity of radiation treatment, substantial research has focused on identifying radiosensitivity-associated genes (12-18). If the expression of a gene can respond to radiation at certain doses and simultaneously cause the apoptosis and/or suppression of tumor cell proliferation, this can be useful for the treatment of cancer.

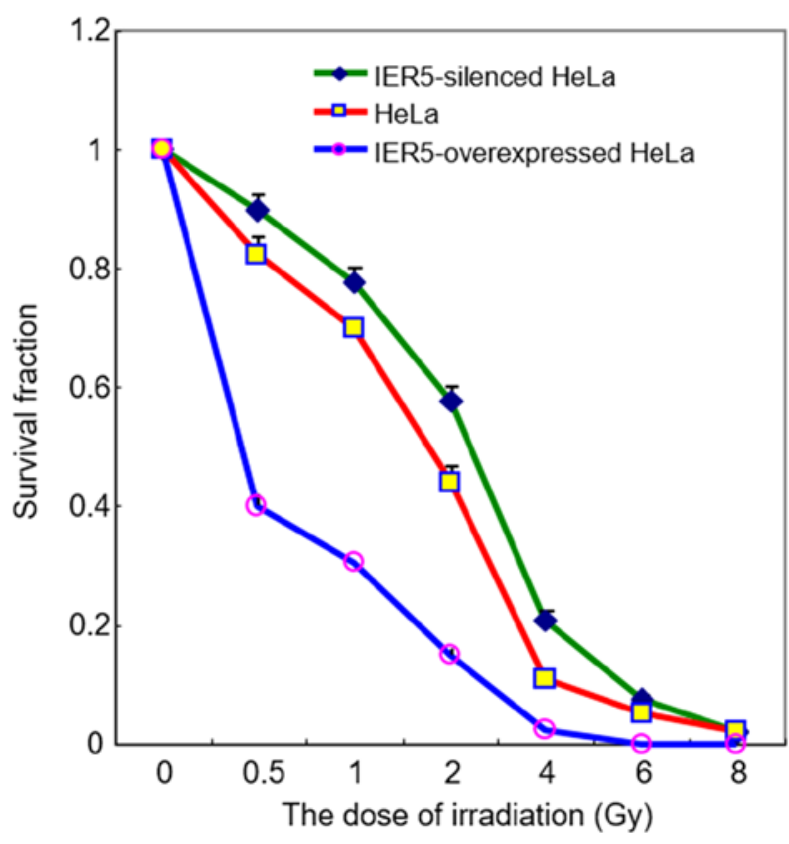

Figure 3. Survival analysis of the three types of HeLa cells following exposure to various doses of radiation. IER5, immediate early response 5 .

Furthermore, the pursuit of radiosensitive genes may help define a dosage standard for radiotherapy based on radiation-induced damage.

Based on these reasons, microarray technology was used to select candidate radiosensitive genes. Using this state-of-the-art assay, it was found that the mRNA expression of IER5 was upregulated following radiation (6). IER5, which belongs to the immediate early response gene family, is located in chromosome 1 (NM-016545), is 2,369 bp long and encodes 308 amino acids (19). The activation of early response genes is considered to be an important primary response to external stimulation in cells $(20,21)$. It has been found that IER5 is overexpressed in the condition of wakefulness and sleep deprivation (21). During the protein- and peptide-bound polysaccharide-induced apoptosis of early human promyelocytic leukemia cells (HL-60), IER5 likely serves a critical role in the formation of brain vessels, and changes occur in its expression in the process of valproic acid-induced neural tube defects, which suggests that this gene likely regulates cell cycle (22). In addition, chromatin immunoprecipitation assays 

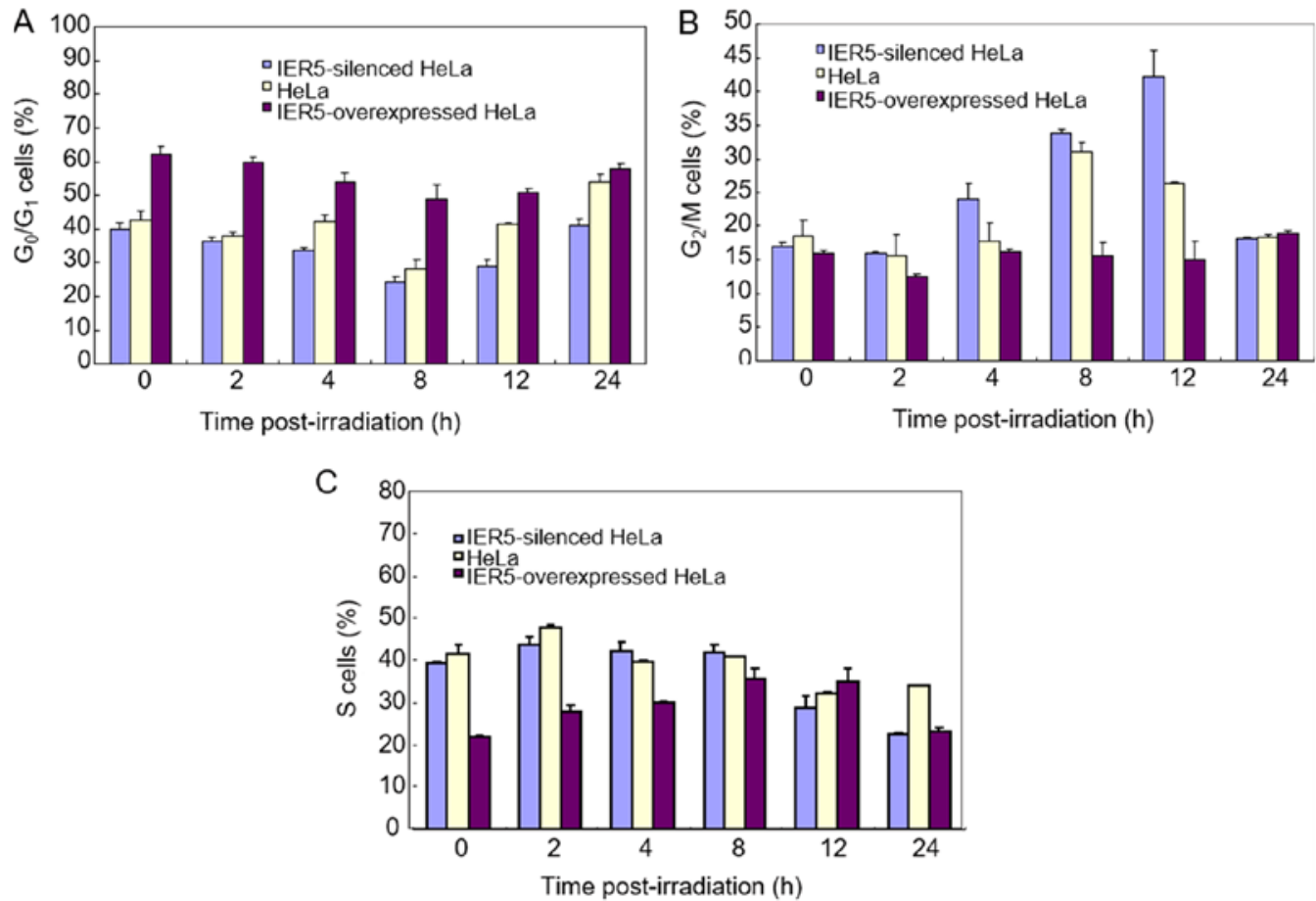

Figure 4. (A-C) Cell cycle analysis for three types of HeLa cells at various time points following radiation with 2 Gy $\gamma$-rays. IER5, immediate early response 5 .

A

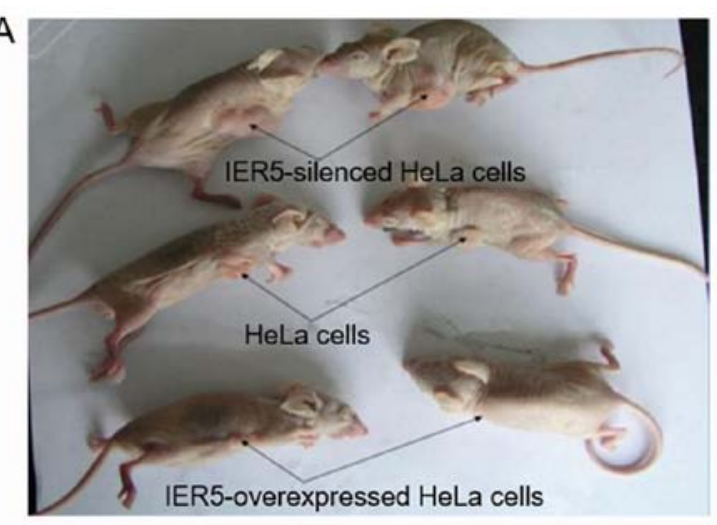

C

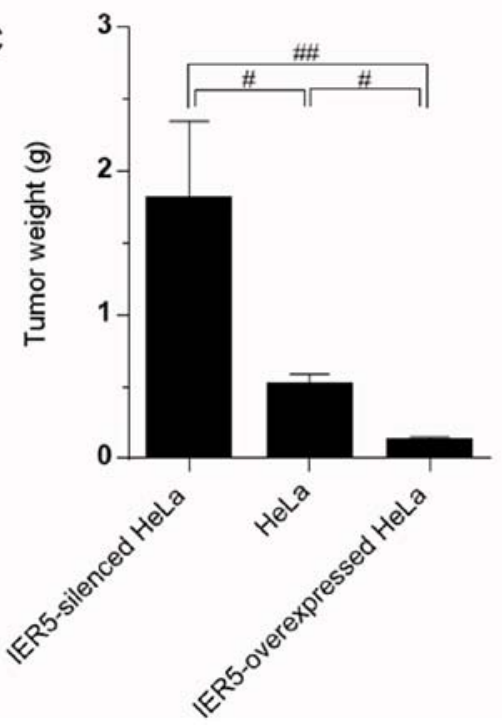

B

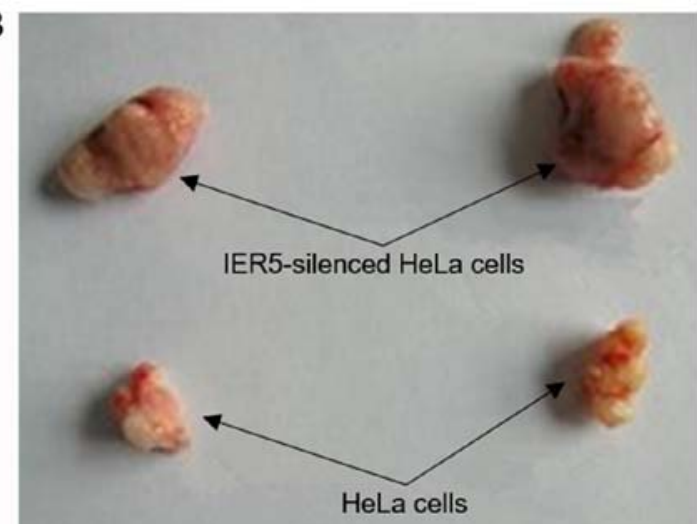

HeLa cells

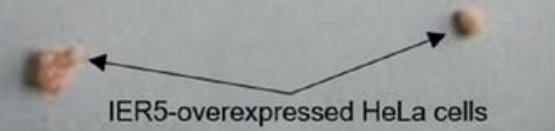

Figure 5. Tumor sizes. (A and B) Typical tumors resulting from the xenografts derived from three types of HeLa cells. (C) Average tumor weights. BALB/c-nu nude mice were injected subcutaneously with the three cell types and the tumors were weighed after 4 weeks. ${ }^{~} \mathrm{P}<0.05$; ${ }^{\# \#} \mathrm{P}<0.05$. IER5, immediate early response 5 . 
have confirmed that radiation induces the overexpression of IER5 $(6,7)$.

In the present study, experiments were performed in order understand the effects of radiation on the IER5 gene and its mechanism of action. First, two stable transfection cell lines were established by methods of gene silencing and overexpression. Compared with the vector control cells, higher percentages of the IER5-siRNA-HeLa cells were in the $\mathrm{S}$ and $\mathrm{G}_{2} / \mathrm{M}$ phases. These results indicate that IER5 may be involved in cell proliferation and tumorigenesis. Of note, IER5 knockdown increased the radioresistance of cells. The IER5-overexpression-HeLa cells exhibited the opposite characteristics of the IER5-siRNA-HeLa cells. For example, the proliferation rate of the IER5-overexpression-HeLa cells was lower. In addition, the ratio of cells in the $G_{0} / G_{1}$ phase was higher than that of the normal and IER5-siRNA-HeLa cells. The results of this experiment suggest that the IER5 gene is involved in cell cycle progression and influences the course of cell division. The present findings demonstrated that radiation inhibited cell proliferation and, among the three cell types assessed, had the greatest impact on the IER5-overexpression-HeLa cells, providing further evidence for the role of IER5 in the DNA damage checkpoint. In addition, the silencing of IER5 accelerated cell division, leading to a larger proportion of cells in the $G_{2}$ phase. This increase may be caused by more efficient arrest of early $S$ phase cells, although a failure of the G1/S checkpoint cannot be excluded. It has been suggested that cell cycle arrest provides the time necessary for irradiated cells to repair DNA lesions and ensure precise chromosome segregation prior to continuation of the cell cycle (6). Therefore, the increased radioresistance that resulted from suppressing the expression of IER5 may be attributed, at least in part, to the activation of cell cycle checkpoints.

The three types of cell lines (normal, IER5-overexpressionHeLa and IER5-siRNA-HeLa) were injected subcutaneously into the limbs of nude mice. Tumors of various sizes resulted from all inoculations. The weights of the xenograft tumors resulting from the IER5-siRNA-HeLa cells were the highest on average. This finding was in agreement with the in vitro experiments, suggesting that the IER5 gene has a biological function in cell division and proliferation. Although the signal transduction pathways of IER5 were not examined in the present study, a previous study revealed the regulating mechanism of the IER5 gene (23). The results of this study also support the findings of the present study to a certain extent.

Radiotherapy is normally used in the treatment of tumors. The radiation administered not only inhibits tumor cell proliferation but also causes more tumor cells to undergo apoptosis. Any genes affected by radiation can cause cancer cells to undergo apoptosis by physical stimulation; such resulting sensitivity to radiation is an important finding in cancer research. The investigations in the present study were designed to examine whether a gene results in characteristics of tumor growth inhibition under conditions of radiation. The xenograft mouse model experiment further demonstrated the consequences of IER 5 dysregulation. The tumorigenic capacity of the IER5-overexpression-HeLa cells in nude mice was the poorest, and that of the IER5-siRNA-HeLa cells was the highest. The consistency between the in vivo and in vitro experimental results has important implications for future investigations of radiotherapy methods for cervical cancer. Certainly, further investigations are required, including those into the regulation mechanism of IER 5 and optimization of the effect of radiotherapy in cervical cancer.

In conclusion, the IER 5 gene affects the radiosensitivity of HeLa cells by decreasing DNA repair and dysregulating cell cycle checkpoints, and it serves an important role in radiation-induced cell death. The present study demonstrated that radiation induced the upregulation of IER 5 mRNA, that IER5 gene modulation affected radiosensitivity and that the overexpression of IER5 decelerated the proliferation of HeLa cells. These results suggest that IER 5 may be a potential radiotherapeutic target for cervical cancer.

\section{Acknowledgements}

Not applicable.

\section{Funding}

This study was supported by grants from the National Natural Science Foundation of China (grant nos. 31770907 and 31640022), the Beijing Natural Science Foundation (grant no. 7172146) and the Natural Science Foundation of Liaoning Province (grant no. 2015020287).

\section{Availability of data and materials}

The datasets used and/or analyzed during the current study are available from the corresponding author on reasonable request.

\section{Authors' contributions}

KKD, FY, HQJ, ZQY, XDL, YMW, PKZ and CJY performed the genetic experiments, participated in the sequence alignment and drafted the manuscript. KKD and XZ conceived the study, participated in its design and coordination, and helped to draft the manuscript. LYD, WC, QG and XYJ participated in the design of the study and performed the statistical analyses. LLY participated in the sequence alignment analysis. All authors read and approved the final manuscript.

\section{Ethics approval and consent to participate}

The Committee for Animal Use at the Capital Medical University approved all experimental procedures performed in the present study.

\section{Patient consent for publication}

Not applicable.

\section{Competing interests}

The authors declare that they have no competing interests. 


\section{References}

1. Yu C, Zhu W, Ji Y, Guo J, Pan P, Han J and Zhou X: A comparative study of intensity-modulated radiotherapy and standard radiation field with concurrent chemotherapy for local advanced cervical cancer. Eur J Gynaecol Oncol 36: 278-282, 2015.

2. Fu ZC, Wang FM and Cai JM: Gene expression changes in residual advanced cervical cancer after radiotherapy: Indicators of poor prognosis and radioresistance? Med Sci Monit 21: 1276-1287, 2015

3. Chu TY, Yang JT, Huang TH and Liu HW: Crosstalk with cancer-associated fibroblasts increases the growth and radiation survival of cervical cancer cells. Radiat Res 181: 540-547, 2014.

4. Xiang L, Xie G, Liu C, Zhou J, Chen J, Yu S, Li J, Pang X, Shi H and Liang H: Knock-down of glutaminase 2 expression decreases glutathione, $\mathrm{NADH}$, and sensitizes cervical cancer to ionizing radiation. Biochim Biophys Acta 1833: 2996-3005, 2013.

5. Yuan W, Xiaoyun H, Haifeng Q, Jing L, Weixu H, Ruofan D, Jinjin Y and Zongji S: MicroRNA-218 enhances the radiosensitivity of human cervical cancer via promoting radiation induced apoptosis. Int J Med Sci 11: 691-696, 2014.

6. Ding KK, Shang ZF, Hao C, Xu QZ, Shen JJ, Yang CJ, Xie YH, Qiao C, Wang Y, Xu LL and Zhou PK: Induced expression of the IER 5 gene by gamma-ray irradiation and its involvement in cell cycle checkpoint control and survival. Radiat Environ Biophys 48: 205-213, 2009.

7. Kis E, Szatmári T, Keszei M, Farkas R, Esik O, Lumniczky K, Falus A and Sáfrány G: Microarray analysis of radiation response genes in primary human fibroblasts. Int $\mathbf{J}$ Radiat Oncol Biol Phys 66: 1506-1514, 2006.

8. Livak KJ and Schmittgen TD: Analysis of relative gene expression data using real-time quantitative PCR and the 2(-Delta Delta C(T)) method. Methods 25: 402-408, 2001.

9. Huang XQ, Chen X, Xie XX, Zhou Q, Li K, Li S, Shen LF and $\mathrm{Su}$ J: Co-expression of CD147 and GLUT-1 indicates radiation resistance and poor prognosis in cervical squamous cell carcinoma. Int J Clin Exp Pathol 7: 1651-1666, 2014.

10. Gaffney DK, Jhingran A, Portelance L, Viswanathan A, Schefter T, Weidhaas J and Small W Jr: Radiation therapy oncology group gynecologic oncology working group: Comprehensive results. Int J Gynecol Cancer 24: 956-962, 2014.

11. Zheng L, Tang W, Wei F, Wang H, Liu J, Lu Y, Cheng Y, Bai X, Yu X and Zhao W: Radiation-inducible protein RbAp48 contributes to radiosensitivity of cervical cancer cells. Gynecol Oncol 130: 601-608, 2013.

12. Moreno-Acosta P, Gamboa O, Sanchez de Gomez M, Cendales R, Diaz GD, Romero A, Balart Serra J, Conrado Z, Levy A, Chargari $C$ and Magné N: IGF1R gene expression as a predictive marker of response to ionizing radiation for patients with locally advanced HPV16-positive cervical cancer. Anticancer Res 32: 4319-4325, 2012

13. Halle C, Andersen E, Lando M, Aarnes EK, Hasvold G, Holden M, Syljuåsen RG, Sundfør K, Kristensen GB, Holm R, et al: Hypoxia-induced gene expression in chemoradioresistant cervical cancer revealed by dynamic contrast-enhanced MRI. Cancer Res 72: 5285-5295, 2012.
14. Baiocchi G, Begnami MD, Fukazawa EM, Oliveira RA, Faloppa CC, Kumagai LY, Badiglian-Filho L, Pellizzon AC, Maia MA, Jacinto AA, et al: Prognostic value of nuclear factor kappa B expression in patients with advanced cervical cancer undergoing radiation therapy followed by hysterectomy. J Clin Pathol 65: 614-618, 2012.

15. Paul S, Barker CA, Turner HC, McLane A, Wolden SL and Amundson SA: Prediction of in vivo radiation dose status in radiotherapy patients using ex vivo and in vivo gene expression signatures. Radiat Res 175: 257-265, 2011.

16. Kim WY, Lee JW, Park YA, Choi JJ, Sung CO, Song SY, Choi CH, Kim TJ, Huh SJ, Kim BG and Bae DS: RAR-beta expression is associated with early volumetric changes to radiation therapy in cervical cancer. Gynecol Obstet Invest 71: 11-18, 2011.

17. Kabacik S, Mackay A, Tamber N, Manning G, Finnon P, Paillier F, Ashworth A, Bouffler S and Badie C: Gene expression following ionising radiation: Identification of biomarkers for dose estimation and prediction of individual response. Int J Radiat Biol 87: 115-129, 2011.

18. Filiano AN, Fathallah-Shaykh HM, Fiveash J, Gage J, Cantor A, Kharbanda $S$ and Johnson MR: Gene expression analysis in radiotherapy patients and C57BL/6 mice as a measure of exposure to ionizing radiation. Radiat Res 176: 49-61, 2011.

19. Williams M, Lyu MS, Yang YL, Lin EP, Dunbrack R, Birren B, Cunningham $\mathbf{J}$ and Hunter K: Ier5, a novel member of the slow-kinetics immediate-early genes. Genomics 55: 327-334, 1999.

20. Göttgens B, Barton LM, Chapman MA, Sinclair AM, Knudsen B, Grafham D, Gilbert JG, Rogers J, Bentley DR and Green AR: Transcriptional regulation of the stem cell leukemia gene (SCL)-comparative analysis of five vertebrate SCL loci. Genome Res 12: 749-759, 2002.

21. Cirelli $\mathrm{C}$ and Tononi G: Gene expression in the brain across the sleep-waking cycle. Brain Res 885: 303-321, 2000.

22. Zeng F, Hon CC, Sit WH, Chow KY, Hui RK, Law IK, Ng VW, Yang XT, Leung FC and Wan JM: Molecular characterization of Coriolus versicolor PSP-induced apoptosis in human promyelotic leukemic HL-60 cells using cDNA microarray. Int J Oncol 27: 513-523, 2005.

23. Nakamura S, Nagata Y, Tan L, Takemura T, Shibata K, Fujie M, Fujisawa S, Tanaka Y, Toda M, Makita R, et al: Transcriptional repression of Cdc25B by IER5 inhibits the proliferation of leukemic progenitor cells through NF-YB and p300 in acute myeloid leukemia. PLoS One 6: e28011, 2011.

This work is licensed under a Creative Commons Attribution-NonCommercial-NoDerivatives 4.0 International (CC BY-NC-ND 4.0) License. 